\title{
A Case of Noonan Syndrome Associated with Nephrotic Syndrome, Pituitary Mass and Pes Varus
}

\author{
Elizabeth Paz-Pacheco, ${ }^{1}$ Ma. Luisa D. Enriquez, ${ }^{2}$ \\ Ramon D.S. Francisco, ${ }^{3}$ Wilfred G. Dee ${ }^{4}$ and Mark Anthony S. Sandoval ${ }^{1}$ \\ ${ }^{1}$ Section of Endocrinology, Diabetes and Metabolism, Department of Medicine, College of Medicine and Philippine General Hospital, \\ University of the Philippines Manila \\ ${ }^{2}$ Physics Department/Biology Department, CENSER, College of Science, De La Salle University \\ ${ }^{3}$ Makati Medical Center \\ ${ }^{4}$ Section of Cardiology, Department of Medicine, College of Medicine and Philippine General Hospital, University of the Philippines Manila
}

\begin{abstract}
We report a case of a Filipino male diagnosed with Noonan syndrome on the basis of facial dysmorphism, chest deformity, short stature, mental and skeletal retardation, pulmonic stenosis and hypogonadism. In addition, he has three clinical features which are not known to be associated with the syndrome and are perhaps being reported for the first time: structurally normal kidneys with nephrotic syndrome, pituitary macroadenoma and pes varus.
\end{abstract}

Key Words: Noonan syndrome, congenital anomalies, genetics, nephrotic syndrome, pituitary mass, pes varus

\section{Introduction}

The Noonan syndrome was first recognized in 1963 when Noonan and Ehmke described nine patients with pulmonic stenosis associated with short stature, hypertelorism, mild mental retardation, ptosis, skeletal anomalies, and undescended testes among the males. ${ }^{1}$ Although Noonan's patients shared several common clinical features with Turner's syndrome, these two clinical entities were easily distinguished by certain phenotypic peculiarities. $^{2}$ The major difference was the absence of chromosomal anomaly among Noonan's patients. Incidence is estimated at one case in 1,000 to $2,500 .{ }^{3}$ In the Philippines, there are already three published cases of Noonan Syndrome-one diagnosed as a child and two as adults. ${ }^{4,5,6 .}$

We report here a case of Noonan syndrome with multiple clinical features (Table 1), three of which were not previously known to be associated with the syndrome.

\section{Case Presentation}

The patient is a 15-year-old male, born full term by spontaneous vaginal delivery from a non-consanguineous marriage, the second child of a 26-year-old mother who

Corresponding author: Elizabeth Paz-Pacheco, MD

Section of Endocrinology, Diabetes and Metabolism

Medical Research Laboratory

Philippine General Hospital

Taft Avenue, Ermita, Manila 1000 Philippines

Telephone: 0917-8418647

E-mail: eppacheco@gmail.com allegedly did not have any illness or drug intake during her pregnancy. At birth, the boy was noted to have a protuberant chest and varus deformity of the left foot. There was webbing of the neck, depressed nasal bridge with broad apex nasi, anti-mongoloid slant of the eyes, low set ears and micrognathia. His phallus remained small and his testes undescended. He was developmentally delayed as he first crawled at five months of age, sat at one and a half years and was unable to arise from a sitting position until two and a half years of age. Despite these, he pursued schooling but had to repeat three grade levels because of poor academic performance. He was in grade 6 when he was seen in the hospital at age 15 years.

He was first seen at age 15 for dyspnea and generalized edema. Six months prior to initial consult, he developed bipedal edema rapidly progressing to anasarca. There was a slight decrease in urine output. There was tea-colored urine, but there was no dysuria. He eventually developed dyspnea, for which he had to be confined in a local hospital. He was diagnosed to have a "kidney disease with cardiac and hepatic complications." Management included digitalis, furosemide and cotrimoxazole and the patient was discharged much improved. However, in a week's time, there was recurrence of all the symptoms. He also developed moderate grade fever associated with cough. To further complicate things, four days prior to admission, he slipped in the bathroom floor, hit his right thigh, resulting in swelling and tenderness of the injured area. Subsequently, vesicles developed, and later ruptured exuding purulent material.

On admission, he was noted to be poorly nourished and was in moderate cardiorespiratory distress. He was awake but irritable, with a normal blood pressure, pulse rate of $112 /$ minute and a respiratory rate of $34 /$ minute. His actual body weight was $26 \mathrm{~kg}$ ( $<5$ th percentile for age) and height was $141 \mathrm{~cm}(<5$ th percentile for age). His head circumference was small for age at $50 \mathrm{~cm}$ as the mean for a 15-year-old male is $56.28 \pm 1.49 \mathrm{~cm} .{ }^{7}$ His chest circumference was likewise small for his age at $70 \mathrm{~cm}$, with the mean value being $81.9 \pm 1.70 \mathrm{~cm}$ for 15 -year-old boys. ${ }^{8}$ 
Table 1. Clinical features of Noonan syndrome present in the patient

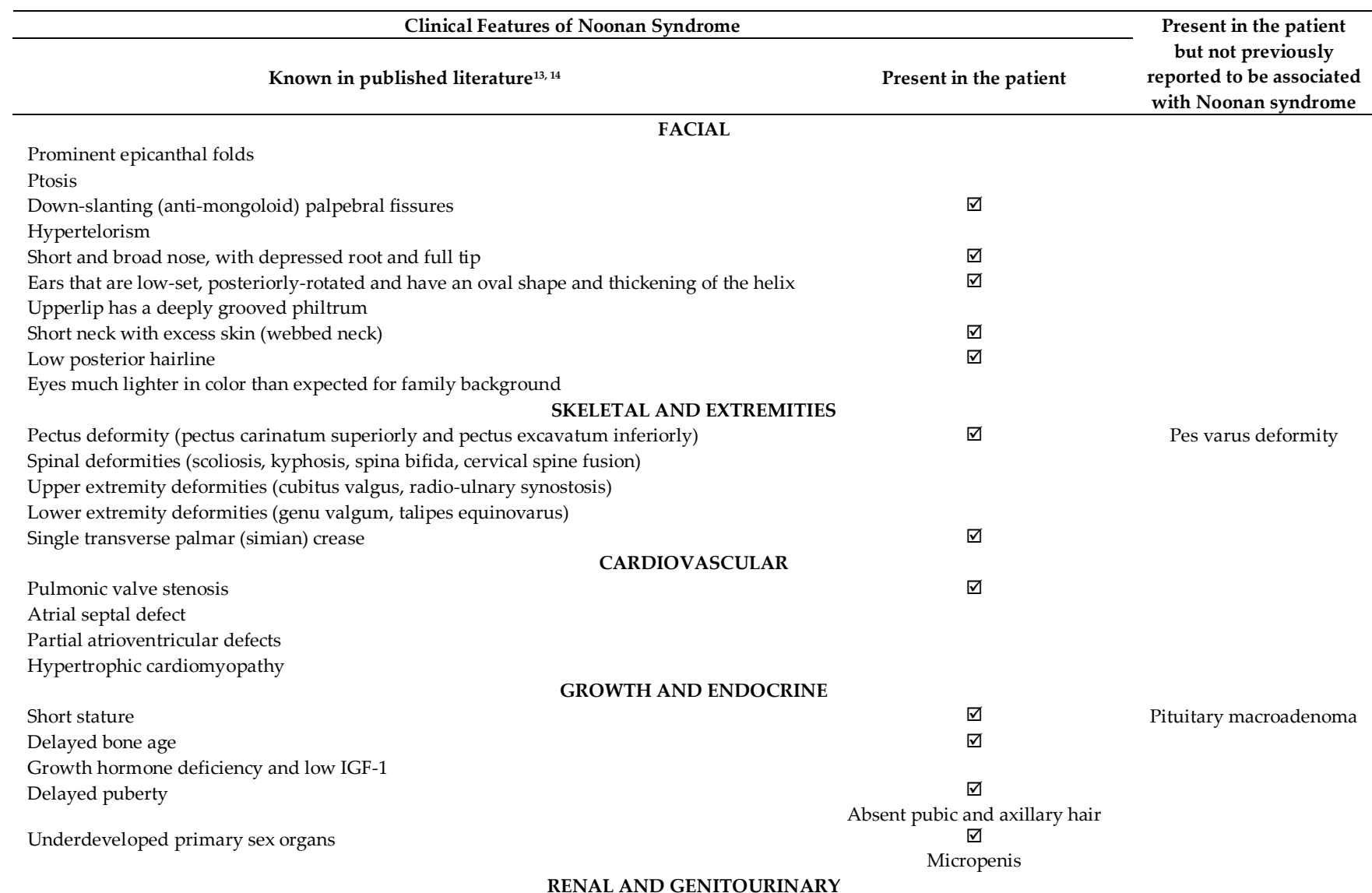

Solitary kidney

Renal pelvis dilatation

Duplicated collecting system

Cryptorchidism

RENAL AND GENITOURINARY

Nephrotic syndrome

Recurrent seizures

Hearing loss

Peripheral neuropathy

Delay in motor milestones

Structural malformation and deformations of the central nervous system (Arnold-Chiari

malformation, microcephaly, macrocephaly)

Lower level of intelligence

NEUROLOGIC, COGNITIVE AND BEHAVIORAL

$\square$

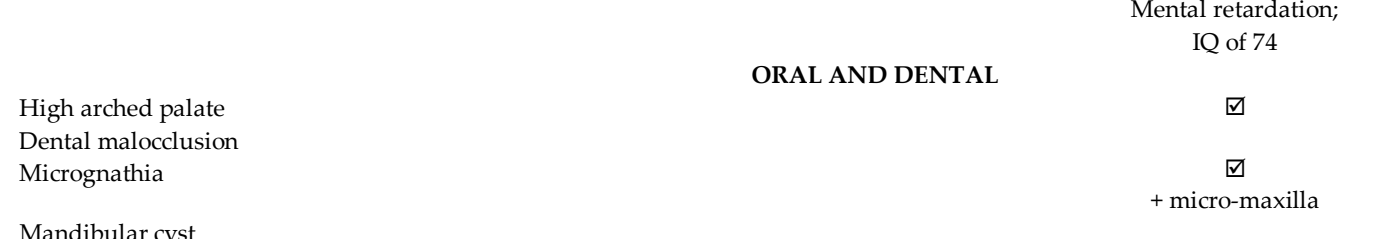

Mandibular cyst

LYMPHATIC

Posterior cervical hygroma (webbed neck)

口

He had slightly pale conjunctivas, facial edema, an antimongoloid slant of the eyes, high arched palate (Figure 1), low set ears, low posterior hairline, webbed neck (Figure 2), and small mandible and maxilla. Funduscopy revealed normal findings with no visual field cuts on perimetry. His intercanthal distance was $3.5 \mathrm{~cm}$ while interpupillary distance was $6.5 \mathrm{~cm}$. Dental evaluation showed chronic apical periodontitis with moderate gingivitis. He had pectus carinatum. His lungs had bronchial breath sounds with rales over mid-lung fields and bases. The point of maximal impulse and apex beat were at the 5 th intercostal space, left midclavicular line. There was a thrill at the base with a 4/6 systolic murmur heard best over the 2nd to the 3rd intercostals spaces, left parasternal border; P2 was not 
increased. His abdomen was globular and a fluid wave was noted. Liver span was $10 \mathrm{~cm}$ and the Traube's space was not obliterated.

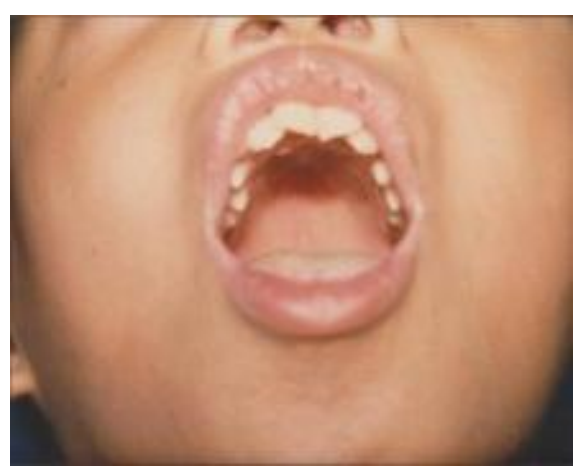

Figure 1. High-arched palate

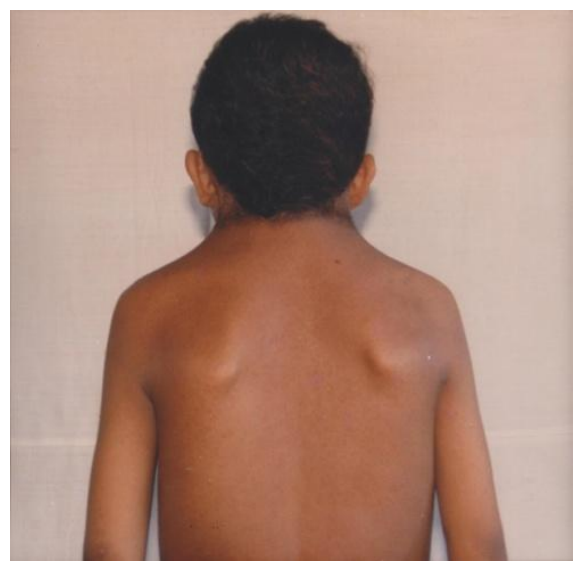

Figure 2. Low posterior hairline, low set ears and webbed neck

Pubic and axillary hair were absent, and penile length was short for age, at only $3.5 \mathrm{~cm}$ (Figure 3 ). The testes were palpable in the inguinal area.

He had a varus deformity of the left foot and a simian crease in the left palm. In addition, cellulitis was noted over his right thigh.

The initial impression was congestive heart failure secondary to a possible rheumatic heart disease, with cellulitis of the right thigh, community acquired pneumonia and a probable nephrotic syndrome. Noonan syndrome was still not recognized at the onset.

\section{Laboratory Investigations}

Further investigation then revealed other problems.

Cardiac. Electrocardiography revealed sinus tachycardia with extreme right axis deviation and right ventricular hypertrophy. An echocardiogram demonstrated right atrial and right ventricular dilatation and hypertrophy, adequate left ventricular function, pulmonary valve stenosis, and mild pericardial effusion.

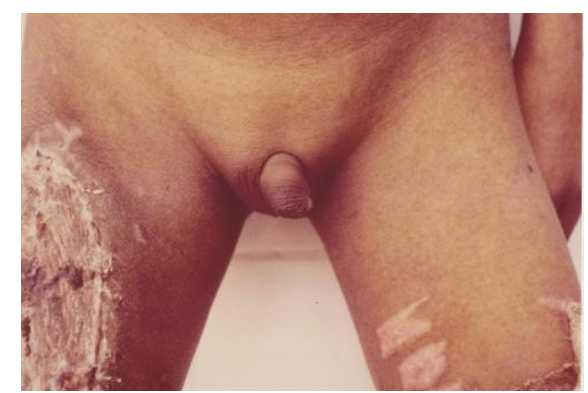

Figure 3. Micropenis, cryptorchidism and absence of pubic hair

Renal. The presence of nephrotic syndrome was documented: +3 to +4 albuminuria; elevated 24-hour urinary protein spillage of 4.13 to $8.13 \mathrm{~g}$; low total serum protein of $32 \mathrm{~g} / \mathrm{L}$ and low serum albumin of $19 \mathrm{~g} / \mathrm{L}$; and high serum cholesterol level of $7.22 \mathrm{mmol} / \mathrm{L}$. Intravenous pyelography and renal ultrasound demonstrated no structural abnormality. Renal biopsy specimen under light and immunofluorescence microscopy revealed focal global sclerosis (Figure 4 ) and trace to +1 irregular mesangial and arteriolar deposits of $\operatorname{IgM}$ and C3, compatible with kidney findings in congenital heart disease and reflux nephropathy. The patient was started on Prednisone at a dose of 1 $\mathrm{mg} / \mathrm{kg} /$ day.

Endocrine. The patient had cryptorchidism (testes were localized at the inguinal region as documented by abdominal CT scan) and micropenis. Serum testosterone was low at $145 \mathrm{ng} / \mathrm{dL}$ (normal: 360-990). Serum follicle stimulating hormone (FSH) and luteinizing hormone (LH) were both low at $1.0 \mathrm{IU} / \mathrm{L}$ (normal: 1.2-5.0) and $1.3 \mathrm{IU} / \mathrm{L}$ (normal: 2.5-9.8), respectively, indicating secondary or tertiary hypogonadism. Pituitary CT scan demonstrated an intrasellar nodule, measuring $1.2 \times 1.0 \times 0.8 \mathrm{~cm}$, consistent with a pituitary macroadenoma. The other anterior pituitary hormone assays were within normal: thyroid stimulating hormone (TSH) $2.8 \mathrm{mU} / \mathrm{L}$ (normal:0-3); prolactin $335 \mathrm{mU} / \mathrm{L}$ (normal: 110-510); growth hormone, baseline at $2.0 \mathrm{ng} / \mathrm{mL}$; after $20 \mathrm{mins}$ of exercise at $19 \mathrm{ng} / \mathrm{mL}$; and after $20 \mathrm{mins}$ of rest at $2.3 \mathrm{ng} / \mathrm{mL}$ (normal: 0-5); serum cortisol (in place of ACTH) 350 mmol/L (normal: 140-555).

Multiple physical anomalies. As was noted, these include short stature, anti-mongoloid slant of the eyes, low set ears, high arched palate, micro-maxilla and micrognathia, webbed neck, low posterior hairline, pectus carinatum, simian crease of left hand, varus deformity of left foot, and skeletal retardation (bone aging revealed an age of 10 years by Greulich and Pyle method) (Figure 5).

Dermatoglyphic analysis of our patient demonstrated intermediate triradii, simian crease, left hand, with a predominance of whorls at the second to fifth digits of both hands. Ulnar loops were noted on both thumbs. Total ridge count could not be determined due to damaged ridges. 


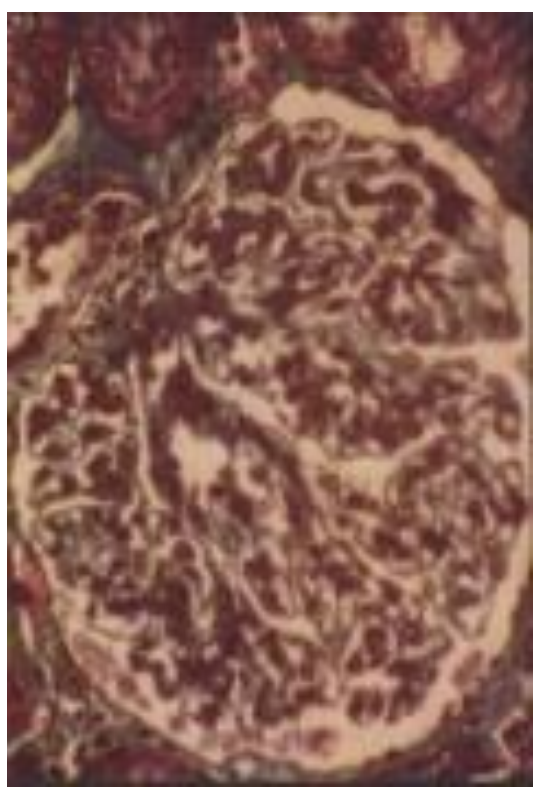

Figure 4. Renal biopsy specimen examined under light microscopy demonstrated focal global sclerosis

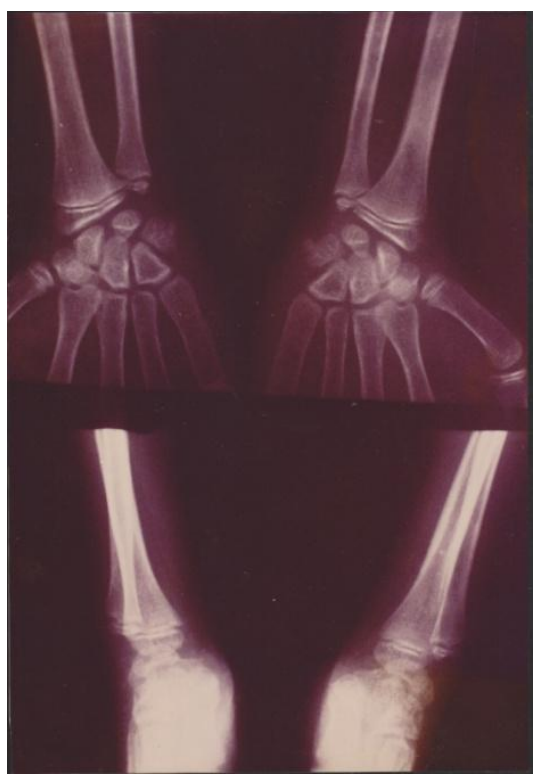

Figure 5. X-rays of the hand performed for bone aging revealed an age of 10 years by Greulic and Pyle method

Mental/Intellectual. Intelligence quotient tests using the Wechsler Adult Intelligence Scale revealed that his intellectual function was borderline with an IQ score of 74 . His difficulties lie in analytical and synthetic skills and concentration ability.

The constellation of these clinical features and anomalies in a male led us to the consideration of Noonan syndrome. Because of the known genetic nature of this syndrome, an extensive family study and pedigree analysis (Figure 6) were performed on all available relatives. These revealed the presence of high arched palate, simian crease and chest prominence (occurring either singly or in combination). Of the 2nd generation consisting of 14 members, three were found to have at least one of the character traits considered. Of the 3rd generation consisting of 42 members (excluding the proband), nine were again noted to have the character traits; of these, seven exhibited high arched palate, three had simian crease of the hand, and another two had chest prominence. No abnormalities were apparent in both parents and an available grandparent. It is worth emphasizing that the finding of high arched palate, simian crease and prominent chest in some of the patient's relatives does not mean that these other relatives also have Noonan syndrome but since this can be inherited in an autosomal dominant manner, a more extensive dysmorphologic evaluation should be done to check if they fit the syndrome or not.

Cytogenetic. Analysis of G-banded metaphase chromosomes prepared from cultured lymphocytes of the proband revealed a normal male karyotype, 46,XY (Figure 7). In addition, interphase nuclei were stained with quinacrine, a fluorescent dye specific for the heterochromatin regions of chromosomes. Each interphase nucleus of the proband showed this intensely stained dot representing the distal portion of the $\mathrm{Y}$ chromosome. ${ }^{9}$

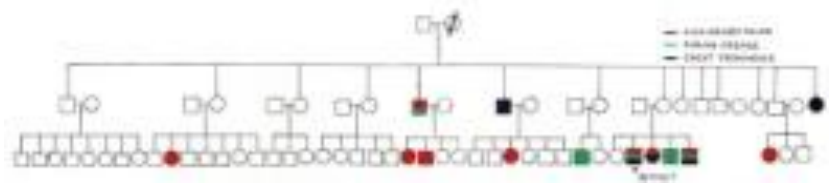

Figure 6. Pedigree analysis showing various following anatomic findings in the proband and his relatives

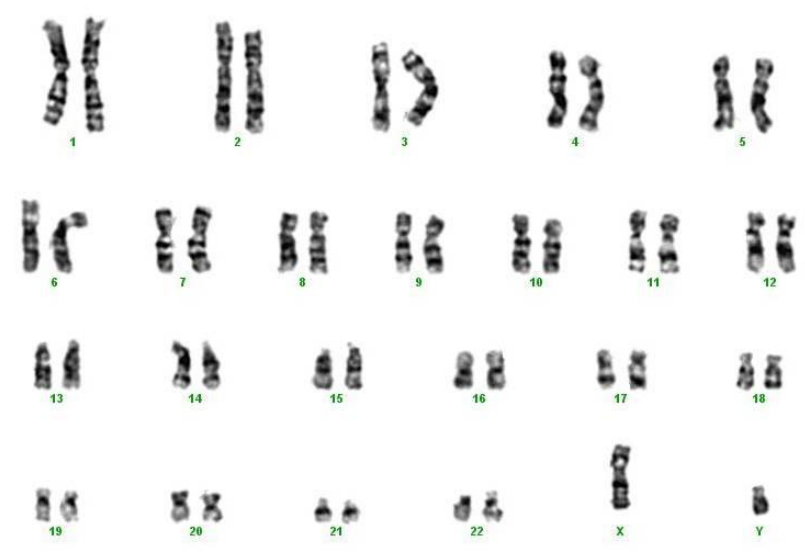

Figure 7. The normal male karyogram of the proband with Noonan syndrome 


\section{Discussion}

Majority of the features that our patient manifested with are commonly seen in other cases of Noonan syndrome, such as the facial features, chest deformity, short stature, mental and skeletal retardation, pulmonic stenosis and hypogonadism. However, structurally normal kidneys with nephrotic syndrome, pituitary mass and varus deformity of the foot are not known to be associated with Noonan syndrome.

Renal anomalies have been described infrequently and usually consist of anatomical defects such as rotational errors, duplication, and hydronephrosis with pyeloureteral obstruction. Nephrotic syndrome was also recently documented in a case of Noonan syndrome. ${ }^{10}$ The case reported by Gupta et al., however, had crossed fused ectopic kidneys grossly and focal segmental glomerulosclerosis histologically. In contrast, the case we report here had structurally normal kidneys by IVP and ultrasound and had focal global glomerulosclerosis histologically.

Known anomalies of the extremities include cubitus valgus, gracile fingers, short and stubby fingers, lymphedema, dystrophic nails, shortened fourth metacarpal, clinodactyly of the fifth finger, palmar simian crease and camptodactyly. ${ }^{11}$ We have not seen a case manifesting with varus deformity based on our literature search.

There has been no reported case of Noonan syndrome with a pituitary mass similar to our patient. However, one patient from Greece was found to have a posterior pituitary tumor which turned out to be a low-grade pilocytic astrocytoma. ${ }^{12}$ Our patient is suspected to have a pituitary macroadenoma based on the CT scan findings but it has not been excised and not subjected to histopathologic confirmation.

\section{Summary}

We reported a 15-year-old Filipino male who presented with 17 clinical features of Noonan syndrome. Because of these findings, the establishment of the diagnosis was not a difficult task. In addition, some of the features he manifested with are not known to be associated with the syndrome and are perhaps being reported for the first time: structurally normal kidneys with nephrotic syndrome, pituitary mass and significant varus deformity of the left foot.

\section{Acknowledgments}

The authors are grateful to Prof. Akira Tonomura and Dr. Fumiko Saito of the Department of Cytogenetics, Tokyo Medical and Dental University, Tokyo, Japan; Dr. Tomotada Enatsu of the FilipinasNippon Cultural Education Foundation, Makati City, Philippines; and Boehringer Mannheim, Philippines.

\section{References}

1. Noonan JA, Ehmke DA. Associated noncardiac malformations in children with congenital heart disease. J Pediatr. 1963; 63:468-70.

2. Summitt RL. Turner's syndrome and Noonan's syndrome. J Pediatr. 1969; 74(1):155-6.

3. Nora JJ, Norah AH, Sinka AK, Spangler RD, Lubs HA. The UllrichNoonan syndrome (Turner phenotype). Am J Dis Child. 1974; 127(1):4855.

4. Gana MO, Pacina A, Cabujat R. To see is to believe: an Ulrich-Noonan syndrome case. Medical Journal of the De La Salle University. 1999; 15(4):29-33.

5. Hernandez, RFR. Noonan's syndrome at a glance: a case report. Philipp J Cardiol. 2003; 31(1):5-10.

6. Cabujat RJB, See JA, Villasenor JA, Tangco RV. Successful percutaneous balloon pulmonary valvuloplasty in an adult Noonan syndrome: a case report. Acta Medica Philippina. 2006; 40(1):58-62.

7. Farkas LG, Posnick JC, Hreczko TM. Anthropometric growth study of the head. Cleft Palate Craniofac J. 1992; 29(4):303-8.

8. Mitova Z. Age and sexual difference in some basic body circumferences throughout 9-15 years of age. Proceedings of the Balkan Scientific Conference of Biology. 2005 May 19-21; Plovdiv, Bulgaria; 2005:61-71.

9. Mitelman F, editor. International System of Human Cytogenetics Nomenclature. Basel, Switzerland: S. Karger Publishers and Cytogenetics and Cell Genetics, Inc; 1995. pp. 27-29.

10. Gupta A, Khaira A, Lal C, Mahajan S, Tiwari SC. Noonan syndrome: crossed fused ectopic kidneys and focal segmental glomerulosclerosis a rare association. Clin Exp Nephrol. 2009; 13(5):531-2.

11. Kronenberg HM, Melmed S, Polonksy KS, Reed Larsen P. William's Textbook of Endocrinology, 11 $1^{\text {th }}$ ed. Philadelphia: W.B. Saunders Co.; 2008. pp. 884-885, 1061.

12. Fryssira H, Leventopoulos G, Psoni S, Kitsiou-Tzeli S, Stavrianeas N, Kanavakis E. Tumor development in three patients with Noonan syndrome. Eur J Pediatr. 2008; 167(9):1025-31.

13. Romano AA, Allanson JE, Dahlgren J, et al. Noonan syndrome: clinical features, diagnosis and management guidelines. Pediatrics. 2010; 126(4):746-59.

14. The Noonan syndrome support group, Inc. Clinical features, diagnosis and management guidelines for those affected by Noonan syndrome [Online]. 2012 [cited 2012 Nov]. Available from www.noonansyndrome.org. 


\section{INSTRUCTIONS TO AUTHORS}

The Acta Medica Philippina is a peer-reviewed general medical and health science journal that is published four times a year by the University of the Philippines Manila and the Department of Science and Technology of the Government of the Philippines, and publishes original scientific papers in the field of basic and clinical medical or health-related research. It has complete editorial independence from its publishers. The editor-in-chief of the Acta is Jose Maria C. Avila, MD. The articles it accepts for publication may be in the form of collective and current reviews, original papers, case reports, lectures, essays, editorials, abstracts or letters to the editor. Original scientific papers and articles of a medical or public health nature are preferred, and the Acta shall accept journal articles from publications from anyone, provided criteria are met. The Acta is the most widely circulated professional health publication in the Philippines and likewise reaches key medical libraries in Asia and the world. It has been in continuous publication since 1939. The online version is now available at www.actamedicaphilippina.com.ph.

All manuscripts, correspondence and editorial business should be sent to Acta Medica Philippina, College of Medicine, University of the Philippines, 547 Pedro Gil Street, P.O Box 593, Manila 1000, Philippines. However, email submissions are also accepted. Manuscripts are received with the understanding that they are not under simultaneous consideration by another publisher. Accepted manuscripts become the permanent property of the Acta Medica and may not be republished without permission from the Editor. These manuscripts are subject to editorial modifications to bring them in conformity with the style of the journal. Statements or views expressed by an author or authors are not the responsibilities of the editor or publisher.

\section{COVER LETTER}

A covering letter must accompany all manuscripts with one author designated as correspondent, providing his complete mailing address, telephone number, e-mail address and fax number. In order for a manuscript to be considered, reviewed or edited, the following statement must be signed by all the authors: "I/We have been sufficiently involved in this work to take public responsibility for its validity and final presentation as an original publication." Whenever applicable, there should also be a written declaration that the article had written/informed consent for publication from the involved subject/s, had conformed with ethical standards, and/or had been reviewed by the appropriate ethics committee. The transmittal letter must include the statement "This paper has not been published and is not under simultaneous consideration for publication elsewhere. This paper has been subjected to ethics review by (name of ethics board or committee, date) and has been endorsed favorably by the said board or committee. I/We hereby confer all copyright ownership/s to the Acta Medica Philippina in the event that this work is published in this journal."

\section{GENERAL GUIDELINES}

1. One original and two duplicate manuscripts should be submitted. An electronic copy must also be submitted on a compact disc or sent by email. If the manuscript is sent by email, the original and duplicate manuscripts need not be submitted unless asked for. The manuscript should be typed double-spaced throughout with $1 \frac{1 / 4}{1} \mathrm{~cm}$ ( $1 \frac{1}{2}$ inch) paragraph indentation, using only one side of each $22 \times 28$ $\mathrm{cm}\left(8 \frac{1}{2} \times 11\right.$ inch) opaque bond paper with 3 -cm margins (11/4 inch) all around. Preferred font styles and sizes are: Times New Roman 12, Arial 11, Tahoma 11, \& Verdana 11.

2. The manuscript should be arranged in sequence as follows: (1) Title Page (2) Abstract (3) Text (4) References (5) Tables (6) Figures \& Illustrations. A manuscript for an original article should not exceed 25 typewritten pages (including tables, figures, illustrations and references). The text for case reports should not exceed 10 pages, including the visual aids and references. All manuscripts not complying with the above shall be promptly returned.

3. References should be selective and pertain directly to the work being reported.

4. All the sheets of the manuscript should be labelled with the family name of the main/first author (all in capital letters) and page number (in Arabic Numeral) printed on the upper right corner.

\section{TITLE PAGE}

1. The title should be as concise as possible. Include only the full names of the authors directly affiliated with the work starting with the first name, middle initial if any, and last name. The highest educational attainment or title of the authors should be included as an attachment whenever appropriate; name and location of no more than three institutional affiliations may be included.

2. If the paper has been presented in a scientific program or convention, provide a footnote giving the name, location and date of the meeting.

\section{ABSTRACT}

For original articles, the abstract should contain no more than 200 words and should have a structured format consisting of the objective, methodology, results and conclusion. For case reports, the abstract should be from 50 to 75 words and need not be structured. At least 3 keywords, preferably using terms from the Medical Subject Headings (MeSH) list of Index Medicus, should be listed horizontally under the abstract for crossindexing of the article.

\section{TEXT}

1. Generally, the text should be organized consecutively as follows: Introduction, Materials and Methods, Results and Discussion (and Conclusion).

2. All references, tables, figures and illustrations should be cited in the text, in numerical order. 
3. Even if commonly employed, all abbreviations should be spelled out once, the first time they are mentioned in the text, followed by the abbreviations enclosed in parentheses. Subsequently, the same abbreviations may be used instead of the long names.

4. All measurements and weights should be in System International (SI) units.

5. Acknowledgements to individuals/groups of persons, or institution/s should be included at the end of the text just before the references. Grants and subsidies from government or private institutions should also be acknowledged.

\section{REFERENCES}

1. References in the text should be identified by Arabic Numerals in superscript on the same line as the preceding sentence.

2. References should be typed double-spaced on a separate sheet. They should be numbered consecutively in the order by which they are mentioned in the text. They should not be alphabetized.

3. All references should provide inclusive page numbers.

4. Journal abbreviations should conform with those used in PubMed.

5. A maximum of six authors per article can be cited; beyond that, name the first three and add " et al."

6. The style/punctuation approved by Acta Medica conforms to that recommended by the ICMJE, which is the ANSI standard style used by the NLM, and should follow the format of the examples shown below:

\section{Lournal}

Putaala J, Metso AJ, Metso TM, et al. Analysis of 1008 consecutive patients aged 15 to 49 with first-ever ischemic stroke. Stroke. 2009;40(4):1195-203.

\section{Website/Internet}

Centers for Disease Control and Prevention, Falls among older adults: summary of research findings [Online]. 2005 [cited 2006 Jan]. Available from http://www.cdc.gov/ncipc/pubres/toolkit/SummaryOfFalls.htm.

$\underline{B o o k}$

Dumitru D, Amato AA, Zwarts MJ. Nerve conduction studies. In: Dumitru D, Amato AA, Zwarts MJ, eds. Electrodiagnostic medicine, $2^{\text {nd }}$ ed. Philadelphia: Hanley and Belfus, Inc; 2002. pp. 159-217.

\section{TABLES}

1. Cite all tables consecutively in the text and number them accordingly. Create tables preferably using a spreadsheet program such as MS Excel with one table per worksheet. Tables should not be saved as image files. The content of tables should include a table number (Arabic) and title in capital letters above the table, and explanatory notes and legends as well as definitions of abbreviations used below. Recommended font is Arial Narrow size 8.

2. Each table must be self-explanatory, being a supplement rather than a duplicate of information in the text. The use of too many tables is discouraged.

\section{FIGURES AND GRAPHS}

1. Figures or graphs should be identified by Roman Numeral/s with titles and explanations underneath. The numbers should correspond to the order in which the figures/graphs occur in the text. It is recommended that figures/graphs also be submitted as image files (preferably as .jpeg or .gif files) of high resolution.

2. All identifying data of the subject/s or patient/s under study such as name, case numbers, etc., particularly in case reports, should be removed.

\section{ILLUSTRATIONS AND PHOTOGRAPHS}

1. All illustrations/photographic prints should be submitted in duplicate and placed in separate envelopes.

2. Black and white glossy prints, unmounted, for photographs and photomicrographs are preferred. However, digital photographs are also accepted, and they should at least be $800 \times 600$ dpi.

3. Computer-generated illustrations which are not suited for reproduction should be professionally redrawn or printed on good quality laser printers. Photocopies are not acceptable.

4. All lettering for illustration should be done professionally and should be of adequate size to retain even after size reduction.

5. The principal author's last name and illustration number should be placed at the back of each illustration/photo print in soft pencil. An arrow on the gummed label indicating the top should be drawn.

6. For photomicrographs, the stain used (ex. H \& E) and magnification (ex. X400) should be included in the description.

\section{Editorial Office Contact Information:}

For comments, questions, and concerns:

Acta Medica Philippina

PM 202, $2^{\text {nd }}$ Flr., Paz Mendoza Building, UP College of Medicine

547 Pedro Gil St., Ermita, Manila 1000

P.O. Box 593

Philippines

Editorial coordinator: Marjorie M. De Lima, RN

Telefax: +632 353-0990

e-mail: editor@actamedicaphilippina.com.ph actamedicaphilippina@cm.upm.edu.ph 